\title{
ESTADO DE COISAS INCONSTITUCIONAL AMBIENTAL: NO CENÁRIO BRASILEIRO
}

\author{
Pâmella de Fátima Antunes Alves ${ }^{1}$ \\ Jaqueline de Paula Heimann²
}

\begin{abstract}
RESUMO: Ao analisar o constitucionalismo brasileiro e o direito a um meio ambiente ecologicamente equilibrado como um direito erga omnes e fundamental, vê-se que há uma problemática sobre se de fato esse direito fundamental está sendo concretizado, posto que reflita não somente sobre a geração atual, mas de forma marcante nas gerações futuras. Com isso, a ação direta de inconstitucionalidade por omissão no 60 busca comprovar de fato a violação desse direito fundamental, com o reconhecimento do estado de coisas inconstitucional ambiental em âmbito nacional. Para isso, são qualificadas as características e requisitos do estado de coisas inconstitucional, já reconhecido no brasil sob outro tema na arguição de descumprimento de preceito fundamental 347/2015, são elencados os pontos principais da ado e ao intérprete são apresentadas possíveis soluções capazes de melhorar e/ou sanar esse estado de inconstitucionalidade.
\end{abstract}

Palavras-chave: Estado de coisas inconstitucional. Meio Ambiente e Direito Fundamental.

ABSTRACT: When analyzing Brazilian constitutionalism and the right to an ecologically balanced environment as a fundamental and erga omnes right, there is a question about whether in fact it is being fulfilled, since it reflects not only on the current generation, but also on future ones. Thus, the Direct Action of Unconstitutionality by Omission No. 6o seeks to prove the violation, with the recognition of the Environmental Unconstitutional State of Things nationwide. The characteristics and requirements of the Unconstitutional State of Things are qualified for this purpose. It is already recognized in Brazil under another theme in the Allegation of Non-compliance with Fundamental Precept 347/2015. The main points of the ADO are listed and the interpreter presents possible solutions to improve and/or remedy this state of unconstitutionality.

Keywords : Unconstitutional state of things. Environment. Fundamental Law.

\footnotetext{
${ }^{1}$ Pós-graduada Direito Ambiental- Universidade Federal do Paraná- UFPR. Advogada - Instituição Toledo de Ensino pela Faculdade Iteana de Botucatu. E-mail: pam_aalves@hotmail.com

${ }^{2}$ Mestre em Economia e Política Florestal pela Universidade Federal do Paraná- UFPR. Pós-graduada em Direito Ambiental- Universidade Federal do Paraná- UFPR. Engenheira Florestal- UFPR. E-mail: jaquelineheimann@yahoo.com.br
} 


\section{INTRODUÇÃO}

O Estado de Coisas Inconstitucional (ECI) é um tema difundido a pouco tempo em âmbito nacional, ou seja, desperta recorrentes dúvidas sobre seus reais requisitos e contrapontos. A presente pesquisa, ao trazer a importância do meio ambiente e desdobrarse sob seu caráter do ponto de vista jurídico e constitucional, abarca os requisitos para a concretização do estado de coisas inconstitucional.

O presente artigo, portanto, ao tratar de um tema tão importante, se justifica não somente no meio acadêmico, mas também sobre sua relevância social diante da crise ambiental enfrentada pelo Brasil.

No mais, almejou-se que cada fator responsável pelo estado de coisas inconstitucional seja identificado diante do meio ambiente, com destaque a violação de direitos fundamentais da pessoa humana, posto a desconsideração do meio ambiente ecologicamente equilibrado pelo Estado Brasileiro. Atentando, portanto, contra ao que se expressa no artigo 225 da Constituição Federal.

O objetivo de demonstração do ECI é caracterizado em matéria debatida junto a Ação Direta de Inconstitucionalidade por Omissão (ADO) no 6o/DF que posteriormente passou a ser Arguição de Descumprimento de Preceito Fundamental, ressaltando os trechos de maiores importância, em consonância as decisões do Ministro Luís Roberto Barroso.

$\mathrm{O}$ artigo iniciou sob a visão de um meio ambiente ecologicamente equilibrado como um direito fundamental da pessoa humana, perfazendo sobre a Constituição Federal. Conseguinte, passou-se a tratar do nascedouro colombiano do estado de coisas inconstitucional e seus principais pontos, inclusive sobre sua consolidação no cenário brasileiro. Para então, adentrar sobre os debates recentes acerca da ADO 6o e sinalizar a matéria constitucional ambiental, para o reconhecimento do estado de coisas inconstitucional ambiental no cenário atual brasileiro.

A pesquisa seguiu os moldes bibliográficos e documental, aplicada sobre fontes primárias. Sendo que a abordagem será qualitativa, sobre a atual decisão presente na ADO 6o/DF e artigos científicos relacionados ao tema em destaque. O método utilizado, foi o método dedutivo, enumerou-se os fatores que compõe o estado de coisas inconstitucional 
no cenário brasileiro, fazendo com que o leitor possa enxergá-lo no âmbito apresentado do Brasil.

E foram apresentadas as decisões presentes já elucidadas na ADO 6o/DF, assim como, demais medidas que possibilitam uma maior adequação estatal para a garantia de um meio ambiente ecologicamente equilibrado.

\section{O MEIO AMBIENTE COMO UM DIREITO FUNDAMENTAL NO BRASIL}

Partindo do Brasil Colonial é possível citar a cultura do pau Brasil, açúcar e mineração do ouro, ou seja, desde seus primórdios os bens naturais do Brasil são explorados, exigindo toda uma crescente na legislação tanto para organização de manejo, quanto para a proteção de tais:

Historicamente, pode-se observar que, desde o Descobrimento e o estabelecimento dos primeiros colonizadores portugueses, a natureza é objeto de exploração para fins econômicos, a exemplo do comércio internacional do paubrasil, usado como madeira ou para a extração de seus pigmentos como corante. Desde aquela fase aos dias atuais, ocorrem formas distintas e fases de exploração dos recursos naturais, que propiciam as bases para a legislação ambiental brasileira e sua aplicação na gestão ambiental (CÂMARA, 2013, p. o2).

Seguindo os parâmetros de Antônio Herman Benjamin (1999, p.02): podemos identificar três momentos (...) históricos na evolução legislativo-ambiental brasileira (...) a fase da exploração desregrada ou do laissez-faire ambiental (...) fase fragmentada (...) e a fase holística. $\mathrm{O}$ autor na fase desregrada expressa que a natureza era símbolo apenas de conquista de novas fronteiras (agrícolas, pecuárias e minerárias).

Seguindo o liame e se deparando com o Brasil republicano vale destacar o Código Civil de 19ı6, que trouxe algumas normas acerca de vizinhança e após a década de 30 já uma maior especificidade de leis ecológicas no Brasil, podendo citar algumas delas como: Decreto 23.793/1934 (Código Florestal), Decreto- Lei no 25/1937 (Proteção ao Patrimônio Histórico e Artístico Nacional), Decretos n 24.643/34 (Código das Águas), Decreto-Lei no 794/38 (Código de Pesca), Decreto- Lei no 1.985/40 (Código de Minas), Decreto-Lei 2.848/4o (Código Penal). Acompanhando o que se expressa Câmara, sobre a evolução dos códigos:

A legislação florestal sofreu grandes transformações após a década de 1930 e vem passando por transformações de uma legislação estritamente florestal e de cunho econômico para uma legislação ambiental mais pontual. Essas transformações têm se processado por meio da edição de códigos com o intuito de proteção, tendo 
se diversificado o controle do Estado sobre os recursos naturais (CÂMARA, 2013, p. 6).

Cumpre enfatizar que o direito ambiental internacional também foi um grande impulsionador para uma política de meio ambiente mais protecionista, podendo destacar a Conferência de Estocolmo como um grande marco em 1972, que trouxe como grandes resultados a criação do Programa das Nações Unidas para o Meio Ambiente- PNUMA e aprovação da Declaração sobre o Meio Ambiente (DIAS, não p., 2020).

Com base na Conferência de Estocolmo, vale destacar o princípio $\mathrm{I}$ o da Declaração:

\begin{abstract}
O homem é ao mesmo tempo obra e construtor do meio ambiente que o cerca, o qual the dá sustento material e lhe oferece oportunidade para desenvolver-se intelectual, moral, social e espiritualmente. Em larga e tortuosa evolução da raça humana neste planeta chegou-se a uma etapa em que, graças à rápida aceleração da ciência e da tecnologia, o homem adquiriu o poder de transformar, de inúmeras maneiras e em uma escala sem precedentes, tudo que o cerca. Os dois aspectos do meio ambiente humano, o natural e o artificial, são essenciais para o bem-estar do homem e para o gozo dos direitos humanos fundamentais, inclusive o direito à vida mesma (ESTOCOLMO, 1972).
\end{abstract}

O princípio em questão serviu como base para o ser humano deixar de ser a figura apenas do "criador", para também se colocar na figura de criatura, concluindo que todas as decisões tomadas decaíram por fim, sobre seu próprio bem estar.

Após, a Conferência de Estocolmo, diversas convenções multilaterais se formaram, mostrando uma crescente na preocupação mundial sobre o meio ambiente. Malgrado, a crescente preocupação com a matéria ambiental, "os progressos nesse período foram insuficientes para alterar a destruição do meio ambiente. De Acordo com uma avaliação realizada pelo PNUMA [...], em 1982, os problemas ambientais tinham piorado" (citado por SILVA; MATTHES, p. 8, 2020).

Portanto, o mundo foi passando de uma visão antropocêntrica, para uma visão biocêntrica e perfazendo a visão do ecocentrismo, percebe-se que o ponto principal passou a ser a vida como um todo tendo grande enfoque para Bioética: Sou vida que quer viver e existo em meio à vida que quer viver (Apud SIGER; MILARÉ, 2014).

E então seguindo nessa perspectiva de visões e evolução e se debruça sobre uma ótica do constitucionalismo brasileiro, até sua evolução ao constitucionalismo contemporâneo. Para isso, algumas constituições foram promulgadas, sendo no total de sete. Todavia, o grande destaque está na Constituição federal Brasileira de 1988 que 
abarcou direitos fundamentais em uma época pós ditadura. Por isso, em todos os sentidos, ela simbolizou o final de um período de autoritarismo no país e seu enfoque sobre a valoração da vida trouxe em seu bojo princípios e direitos fundamentais que antes não eram salvaguardados, conforme preceitua Calza: Depois de um período de privação de direitos, a Lei Maior veio repleta de direitos fundamentais, e o fato de ser oposta a fase anterior de ditadura acaba por ser uma de suas marcas (2015, não p.).

Com a Constituição Federal de 1988 e para o entendimento do meio ambiente ecologicamente equilibrado como um direito fundamental dois pontos são importantes sendo esses: o direito fundamental a dignidade humana e o princípio ambiental de um meio ambiente ecologicamente equilibrado. Com esse liame interligado estritamente a vida do homem, o direito a um meio ambiente equilibrado se consolida como um direito fundamental de terceira geração:

[...] modernamente, protege-se, constitucionalmente, como direitos de terceira geração os chamados direitos de solidariedade ou fraternidade, que englobam o direito a um meio ambiente equilibrado ${ }^{3}$, uma saudável qualidade de vida, ao progresso à paz [...] e a outros direitos difusos, que são, no dizer de José Marcelo Vigliar, os interesses de grupos menos determinados de pessoas, sendo que entre elas não há vínculo jurídico ou fático muito preciso (MORAES, 2005, p. 27).

Cumpre enfatizar os ensinamentos de Milaré, sobre essa visão do meio ambiente e direito fundamental:

Há pressupostos para isso; há requisitos mínimos para que o homem possa viver com dignidade, em um ambiente saudável. Nesse sentido, não existe qualidade de vida sem qualidade ambiental, e é exatamente esse liame indissociável entre os dois conceitos que erige o direito ao meio ambiente ecologicamente equilibrado a direito humano fundamental e, mais que isso, a uma das espécies dos chamados direitos personalíssimos (2014,p.123).

Portanto, essa consolidação do direito fundamental a um meio ambiente equilibrado está concretizada no capítulo V, da Constituição Federal Brasileira em seu artigo 225:

Art. 225. Todos têm direito ao meio ambiente ecologicamente equilibrado, bem de uso comum do povo e essencial à sadia qualidade de vida, impondo-se ao poder público e à coletividade o dever de defendê-lo e preservá-lo para as presentes e futuras gerações.

\footnotetext{
${ }^{3}$ Conforme afirmou o Supremo Tribunal Federal, "Direito ao meio ambiente ecologicamente equilibrado: a consagração constitucional de um típico direito de terceira geração" (RTJ 155/206).
} 
O Direito Ambiental seguiu lentos passos para chegar onde se encontra hoje no patamar brasileiro, com um capítulo destinado a ele e sendo o direito a um meio ambiente ecologicamente equilibrado, um direito das gerações presentes e futuras, segue citação:

O direito ao ambiente é um direito subjetivo fundamental, de natureza personalíssima, e tendo como função conservar o meio ambiente sadio e ecologicamente equilibrado em favor do titular e de terceiros, inclusive das gerações futuras (citado por AMARAL; MILARÉ, 2014, p.124).

Como um ponto importante e necessário cabe ao Poder Público proteger o meio ambiente e garantir que todos usufruam da melhor forma, visto que no parágrafo Io do art. 225 da CF são expressas as obrigações do poder público para a garantia desse direito. Consoante:

\begin{abstract}
A especial característica do princípio e a de que o desequilíbrio ecológico não é indiferente ao Direito, pois o Direito Ambiental realizasse somente numa sociedade equilibrada ecologicamente. Cada ser humano só fruirá plenamente de um estado de bem-estar e de equidade se lhe for assegurado o direito fundamental de viver num meio ambiente ecologicamente equilibrado. A Constituição do Brasil, além de afirmar o direito ao meio ambiente ecologicamente equilibrado, determina que incumbe ao Poder Público proteger a fauna e a flora, interditando as práticas que coloquem em risco sua função ecológica ou provoquem a extinção de espécies (art. 225, caput e seu § Ia, VII) (MACHADO, 2013, p. 66).
\end{abstract}

Nesse mesmo liame, Machado (2013, p.61): Destarte, o meio ambiente é considerado como "um patrimônio público a ser necessariamente assegurado e protegido, tendo em vista o uso coletivo" (art. 2, I Lei de Política Nacional do Meio Ambiente).

Convém destacar, então que a lesão a esse direito não é apenas uma ofensa a um específico mandamento obrigatório, mas a todo o sistema de comando.

\title{
${ }_{3}$ O ESTADO DE COISAS INCONSTITUCIONAL: REQUISITOS E NASCEDOURO
}

O estado de coisas inconstitucional tem origem embrionária na Corte Colombiana através da Sentencia de Unificacion SU-559 de 1997, versando sobre a aplicação de direitos previdenciários de professores e se consolidando como uma técnica decisória:

A teoria do estado de coisas inconstitucional (ECI) surgiu na Colômbia envolta num processo de judicialização da política e do crescimento do ativismo judicial, precisamente em julgamento da Corte Constitucional Colombiana, a partir da decisão SU-559, de o6 de novembro de 1997, influenciada nos structural remedies dos Estados Unidos (CAMPOS, 2015, não p.). 
No que concerne aos pressupostos existem três ao todo, sendo necessária a caracterização de cada um deles para a instrumentalização do Estado de Coisas Inconstitucional:

a) situação de violação generalizada de direitos fundamentais; b) inércia ou incapacidade reiterada e persistente das autoridades públicas em modificar a situação; c) a superação das transgressões exigir a atuação não apenas de um órgão, e sim de uma pluralidade de autoridades (ALVES e SOUZA, 2020, p. 3).

Esses três pressupostos apresentados são necessários para a descrição e reconhecimento do Estado de Coisas Inconstitucional, sendo uma soma de fatores interligados e que juntos formam uma situação fática que não exime a movimentação dos três poderes para seu saneamento.

O Estado de Coisas Inconstitucional pode ser suscitado sobre vários cenários, conforme o que segue:

O ECI, enquanto expressão social da ação de tutela, pode ser declarado para proteger os direitos econômicos, sociais e culturais (DESC), como tem sido o caso da declaração de proteção dos direitos dos pensionistas, da saúde da população prisional ou de toda a componente social que apelou à declaração de populações deslocadas do ECI; Mas também, para proteger os direitos civis e políticos, como especificamente feito com a declaração de proteção da vida dos defensores dos direitos humanos, ou a proteção do direito à igualdade dos requerentes. Tradução livre (PEÑA, 20II, p.13).

No Brasil, a primeira oportunidade em que o Supremo Tribunal Federal reconheceu o tema, foi em 27 de agosto de 2015, na decisão em medida cautelar da Arguição de Descumprimento de Preceito Fundamental (ADPF) no 347 do Distrito Federal.

A Arguição de Descumprimento de Preceito Fundamental 347/2015, foi proposta pelo PSOL- Partido Socialismo e Liberdade que tratava sobre o reconhecimento desse Estado de Coisas Inconstitucional frente ao sistema Prisional Brasileiro. Em sede de liminar foi reconhecido o ECI e algumas medidas liminares foram propostas para serem cumpridas pelo Estado, dentro de um prazo determinado.

$\mathrm{Na}$ ADPF 347/2015, o partido indicou a essência dos pressupostos que caracterizam o estado de coisas inconstitucional no contexto do sistema carcerário brasileiro:

(a) violação generalizada e sistêmica de direitos fundamentais; b) inércia ou incapacidade reiterada e persistente das autoridades públicas em modificar a conjuntura; c) situação que exige a atuação não apenas de um órgão, mas sim de uma pluralidade de autoridades para resolver o problema, pugnando pelo seu reconhecimento, pelo Supremo Tribunal Federal e, por consequência, o julgamento procedente do pedido para determinar uma série de medidas (no total, 
oito) para os juízes e tribunais do país, para o Conselho Nacional de Justiça e para a União (ALVES; SOUZA, 2020, p. 5).

Em decisão cautelar, o STF deferiu os pedidos referentes às audiências de custódia e à liberação das verbas do FUNPEN (fundo penitenciário nacional), tendo o Ministro Marco Aurélio reconhecido o Estado de Coisas Inconstitucional no Sistema Carcerário Brasileiro, portanto, passou a ter respaldo não apenas doutrinário, mas jurisprudencial no Brasil.

E recentemente com algumas decisões da Ação Direta de Inconstitucionalidade por Omissão n. 6o, o Ministro Roberto Barroso registrou a possibilidade de existência de um estado de coisas inconstitucional em matéria ambiental.

\section{AÇÃO DIRETA DE INCONSTITUCIONALIDADE POR OMISSÃO №6o}

Em meados de 2020 aportou no Supremo Tribunal Federal a Ação Direta de Inconstitucionalidade por Omissão número 6o do Distrito Federal (ADO 6o) proposta pelos seguintes partidos: Partido Socialista Brasileiro (PSB); Partido Socialismo e Liberdade (PSOL); Partido dos Trabalhadores (PT) e Rede Sustentabilidade. No polo passivo da ação encontra-se a União. A alegação dos autores indicava a omissão do Governo Executivo Federal em face da gestão do Fundo Clima e de outras matérias de interesse ambiental correlacionados como a mudança climática, o aquecimento da Terra e a preservação das florestas tropicais.

Sobre o início da crise ambiental brasileira e suas reflexões cumpre citar:

[...] a partir da (in)efetividade das normas constitucionais ambientais. Instrumentos preventivos de gestão ambiental pública- como licenciamento ambiental, Agenda 2i Local, Sistema integrado de Gestão Ambiental- quando negligenciados pela Administração Pública, configura violação do comando constitucional (art. 225). Problemas relacionados ao saneamento básico, recursos hídricos, resíduos sólidos, poluição, matriz energética, mobilidade urbana, motivam a rediscussão da harmonização e independência dos Poderes da República, de modo a blindar a segurança jurídica da Constituição, em especial a efetividade dos direitos fundamentais (MOURA, 2017, p. 15).

Tudo começou com a distribuição das Ações Diretas de Inconstitucionalidade por Omissão no 59 e 6o; posto que a $\operatorname{ADO}^{\mathrm{o}} 59$ tratava do Fundo Amazônia e a $\operatorname{ADO}$ no6o tratava do Fundo Clima. Ocorre que a ADO 59 prosseguiu com seu trâmite por se tratar apenas de situações que envolviam omissões, e não se respaldando sob o ECI. Ao contrário da ADO no6o que por trazer consigo traços de ECI e situação que envolvia tanto ação, 
quanto omissão estatal foi convertida para ADPF 708/2020. Vale esclarecer, portanto, o cabimento da Ação direta de inconstitucionalidade por omissão:

O objetivo pretendido pelo legislador constituinte de 1988 , com a previsão da ação direta de inconstitucionalidade por omissão, foi conceder plena eficácia às normas constitucionais, que dependem de complementação infraconstitucional. Assim, tem cabimento a presente ação, quando o poder público se abstém de um dever que a Constituição lhe atribuiu (MORAES, 2005, p. 690).

Nesse liame tem-se, que a Arguição de Descumprimento de Preceito fundamental traz como seu conceito:

Caberá, preventivamente, arguição de descumprimento de preceito fundamental perante o Supremo Tribunal Federal com o objetivo de se evitar lesões a princípios, direitos e garantias fundamentais previstos na Constituição Federal, ou, repressivamente, para repará-las, quando causadas pela conduta comissiva ou omissiva de qualquer dos poderes públicos (MORAES, 2005, p. 70r).

Portanto, no tocante à $\mathrm{ADO} 60$ que posteriormente se fez $\mathrm{ADPF}$ 708/2020, em sua petição inicial é expressa a omissão estatal ao fundo clima e demais questões ambientais, assim como ações que ferem os preceitos de tal, como: A mudança climática, o aquecimento da Terra e a preservação das florestas tropicais. Em seu decorrer é exposto o direito ambiental como um direito fundamental e as consequências graves econômicas e sociais advindas de políticas ambientais que descumprem compromissos internacionais assumidos pelo Brasil. Portanto, vale destacar a responsabilidade do Poder Público para preservar o meio ambiente, conforme o artigo 225 da Constituição Federal.

Entre as ações e omissões do Estado foram elencadas as seguintes, consoante a petição:

Entre os atos comissivos apontados pelos requerentes, incluem-se: (i) a redução dos orçamentos e dotações relacionadas ao controle do desmatamento e ao fomento de formas sustentáveis de produção; (ii) o licenciamento de obras de infraestrutura, sem adequada avaliação de impacto; (iii) a desestruturação dos órgãos ambientais federais; (iv) o esvaziamento das atribuições do Ministério do Meio Ambiente; (v) a nomeação para cargos importantes de pessoas sem afinidade com a área ambiental; (vi) orientação pública para cessação da demarcação de Terras Indígenas; além de (vii) cortes orçamentários na política ambiental ainda maiores do que os que vinham ocorrendo no passado.

Quanto às omissões apontadas pelos requerentes, destacam-se: (i) a falta de reuniões do Comitê Gestor do Fundo, mantido inoperante durante todo o ano de 2019; (ii) a não aprovação do Plano Anual de Aplicação de Recursos, quer para 2019, quer para 2020; (iii) a manutenção de “vultosos recursos 'em caixa' com a rubrica específica de financiar ações voltadas à mitigação de emergências climáticas". No que respeita ao último ponto, os requerentes esclarecem que havia autorização orçamentária para aplicação de $\mathrm{R} \$$ 8.050.00o,oo não 
reembolsáveis para tal fim, tendo sido empenhados apenas $\mathrm{R} \$ 718.074,00$; bem como de mais $\mathrm{R} \$ 543$ milhões reembolsáveis, dos quais foram empenhados apenas $\mathrm{R} \$ 348$ milhões, cujo direcionamento ao BNDES, todavia, não se concretizou. Ainda segundo os requerentes, o demonstrativo de movimentação financeira do Fundo Clima do ano de 2019 apontaria um saldo disponível de R 250.074.00o,oo (Petição Inicial- Arguição De Descumprimento De Preceito Fundamental 7o8).

O fundo Clima objeto da ação tem como conceito: $O$ Fundo Nacional sobre Mudança do Clima é um instrumento da Política Nacional sobre Mudança do Clima. Ele tem por finalidade financiar projetos, estudos e empreendimentos que visem à redução de emissões de gases de efeito estufa e à adaptação aos efeitos da mudança do clima (MINISTÉRIO DO MEIO AMBIENTE, não p. 20I2).

No decorrer da petição inicial da ADO 6o é destacado o ano de 2019 em que o desmatamento aumentou na ordem média de mais de 30\%, além do avanço de queimadas, de invasões de terras indígenas e de unidades de conservação em proporções alarmantes. E, de acordo com o Imazon, o desmatamento dos últimos il meses cresceu cerca de 50\% na Amazônia (Petição Inicial- Arguição De Descumprimento De Preceito Fundamental 708).

È pautada na inicial a atual questão da pandemia, que é vista como uma "cortina de fumaça" incentivando o afrouxamento das fiscalizações sob a proteção ambiental.

No decorrer da ADPF 708/2020 foi deferida pelo Ministro Luis Roberto Barroso as seguintes medidas, a fim de analisar os recursos do Fundo Clima, para comprovar se houve ou não violações as violações elencadas:

\footnotetext{
Admito o Observatório do Clima como amicus curiae, dada sua representatividade e expertise. 2. Intimem-se a União e o Banco Nacional do Desenvolvimento Econômico e Social BNDES para, no prazo de 5 dias: (i) comprovarem a destinação de recursos do Fundo Clima reembolsáveis e não reembolsáveis que se afirma ter ocorrido; (ii) manifestarem-se sobre as últimas petições dos Requerentes (Pet 171/202I) e do Observatório do Clima (Pet 95737/2020); e (iii) informarem o quantitativo total de recursos já comprometidos com a execução de projetos e com financiamentos já celebrados, bem como o valor remanescente de recursos ainda em aberto.
}

O último andamento se pauta na intimação do Procurador Geral da República, e no decorrer da ação foi indeferida a antecipação de tutela que pleiteava a suspensão do financiamento do projeto "Lixão Zero", do Governo do Estado de Rondônia.

\section{POSSÍVEIS MEDIDAS APAZIGUADORAS}

O agente principal para sanar esse estado de coisas inconstitucional no meio ambiente brasileiro é o Poder Público, com isso cabe a ele as seguintes medidas acompanhando o que se molda sobre a $\mathrm{ADO} 60 / \mathrm{DF}$ (2020) em sede de cautelar e mérito: 
(i)suspenda o comportamento lesivo consistente em não tomar as medidas administrativas necessárias para disponibilizar os recursos relativos ao Fundo Clima; (ii) apresente o Plano Anual de Aplicação de Recursos do Fundo para o ano de 2020 e não se omita de elaborar os demais planos anuais cabíveis; (iii) se abstenha de contingenciar recursos do Fundo. No mérito, postulam o reconhecimento da inconstitucionalidade da conduta da União na condução do Fundo Clima, bem como na adoção das medidas de proteção ambiental pertinentes à mitigação de mudanças climáticas (Ação Direta de Inconstitucionalidade por Omissão 6o Distrito Federal).

Todavia, não basta que o Poder Público se paute apenas no tema apresentado pela ADO 6o, devendo cumprir melhorias em todas as vertentes do meio ambiente, para assim proporcionar o mínimo existencial para as gerações presentes e futuras e atingir o equilíbrio destacado na constituição federal:

O estado de equilíbrio não visa à obtenção de uma situação de estabilidade absoluta, em que nada se altere. É um desafio científico, social e político permanente aferir e decidir se as mudanças ou inovações são positivas ou negativas (MACHADO, 2013, p. 64).

Além de outras medidas tem-se o diálogo interinstitucional, capaz de gerar uma força tarefa em prol de um bem comum, a obediência as normas constitucionais. Sendo a comunicação entre os três poderes de suma importância para a garantia de preservação do meio ambiente. Cumpre mencionar:

O reconhecimento do estado de coisas inconstitucional vem na tentativa de superar bloqueios desacordos políticos, possibilitando o aumento do diálogo interinstitucional, a fim de garantir a proteção de direitos fundamentais que, até então, não são concretizados ou os são de forma deficiente (untermassverbot) (ALVES; SOUZA, 2020, p. 5).

Cumpre citar o poder Judiciário e seu protagonismo na eficácia das normas ambientais:

O Poder Judiciário como o protagonista da medida coercitiva que restabeleça a segurança jurídica e a efetividade da norma constitucional. A Constituição, ao preceituar a harmonização entre os Poderes, conduz ao diálogo de correção. Quando um dos poderes não atingir a máxima responsabilidade a ele inerente caberá uma correção-comando-tarefa que o obrigue a cumpri-la na sua integralidade. A independência dos Poderes não significa blindagem de eximi-lo de um comando de correção - obrigação de executar suas responsabilidades constitucionais (MOURA et al, 2017, p. 16).

O Brasil possui um grande número de políticas ambientais, as quais deveriam ser realizadas e fiscalizadas de maneira melhor. Para isso, os órgãos ambientais devem proporcionar uma melhor fiscalização, assim como, receber o devido auxílio do poder 
público. Por isso, as políticas públicas são essenciais na disseminação de ações que valorizem o meio ambiente, com isso os incentivos propostos por elas abrem caminhos tanto nos campos de investimento quanto nos campos de pesquisa:

\begin{abstract}
Admito que políticas públicas seja uma expressão vaga e pouco convidativa. Uma grande descoberta, como um novo tipo genial de bateria, seria bem mais atraente do que incentivo público que possibilitou sua invenção. Mas a descoberta nem existiria se o governo não gastasse dinheiro com pesquisa, com medidas concebidas para tirar a pesquisa do laboratório e levá-la ao mercado e com regulamentações que produziram mercados e facilitaram seu emprego em larga escala. (GATES, 2021, p. 215)
\end{abstract}

Vale destacar que o reconhecimento do Estado de Coisas inconstitucional é medida excepcional, mas caso reconhecido será uma grande medida de proteção ao meio ambiente, consolidando ainda mais o direito fundamental a um meio ambiente ecologicamente equilibrado: A aplicação do ECI Ambiental é uma excepcionalidade para corrigir uma obrigação de não fazer ou impor a obrigação de fazer (funções precípuas e fiscalizatória) (MOURA et al, 2017, p. 16).

E como ponto que vem sendo destacado há tempos, apesar de parecer ineficaz as ações de conscientização da importância do meio ambiente são de suma importância para criar uma consciência cultural de preservação, seja através de programas educacionais, propagandas e/ou investimento nas pesquisas, que visam encontrar formas de diminuir os danos ambientais no território brasileiro, assim como, formas de prevenção.

\title{
CONSIDERAÇÕES FINAIS
}

Como partida da pesquisa há o caminhar do meio ambiente ecologicamente equilibrado, para se expressar como direito fundamental no cenário brasileiro. Tendo como ponto chave de tal situação o artigo 225 da Constituição Federal de 1988, como marco desse direito fundamental.

Conseguinte elenca-se a figura do Estado de Coisas Inconstitucional, desde seu conceito ao seu primeiro contato com o âmbito jurídico brasileiro, para então seu reconhecimento em tema diverso através da ADPF 347/2015. Retomando a figura do ECI em sede da ADO n.6o, que se fez em ADPF 708/2020, a qual tratava de um possível Estado de Coisas Inconstitucional sob o meio ambiente Brasileiro. 
Portanto, do apresentado da ADPF 708/2020 de forma teórica é possível se caracterizar o ECI em matéria ambiental diante do cenário brasileiro, com grandes déficits ambientais e aumento de desmatamento, assim como, o não uso correto dos recursos financeiros responsáveis pela manutenção de fundos e programas ambientais. Todavia, a ADPF ainda está em curso e sem reconhecimento de medidas cautelares sobre o assunto.

Certamente, caso ocorra o reconhecimento do ECI em matéria ambiental pelo Ministro Luis Roberto Barroso, será mais um marco sobre o direito ambiental brasileiro. Perfazendo, a necessidade de ação dos três poderes, funcionando como remédios estruturais, para sanar as inconstitucionalidades sofridas pelo direito fundamental a um meio ambiente ecologicamente equilibrado, as quais refletem não somente sobre as gerações presentes, mas em que pese sobre as gerações futuras na garantia para o mínimo existencial, que caso não ocorra atinge demais direitos fundamentais como: direito a vida, direito a dignidade humana, direito a propriedade, dentre outros.

Salienta-se que para o desenvolvimento sadio e equilibrado do meio ambiente no Brasil é necessário um conjunto de ações, que envolvam tanto o Governo, cidadãos, e entes privados. Desde as políticas públicas, como a conscientização que reflete nas ações da sociedade como um todo.

\section{REFERÊNCIAS}

ALVES, Jaime Leônidas Miranda; SOUZA, Maria Cláudia da Silva Antunes de. Proteção Ambiental: entre o direito da sustentabilidade e o estado de coisas inconstitucional. Revista de Direito e Sustentabilidade. e-ISSN: 2525-9687 | Encontro Virtual | v. 6 | n. 2 | p. $63-78 \mid \mathrm{Jul} /$ Dez. 2020.

ÁNDREA, Gianfranco Faggin Mastro. Estado de Coisas Inconstitucional no Brasil. I. Ed. Rio De Janeiro: Lumen Juris, 2018.

BENJAMIN, Antônio Herman V. Introdução ao Direito Ambiental Brasileiro. Revista de Direito Ambiental. vol. I4/1999. p. $48-82$. Abr - Jun / 1999. Disponível em: Texto or Introdução ao Direito Ambiental - Herman Benjamin.pdf (usp.br). Acesso em: I2 set 202I.

CALZA, Morgana. Direito, Ditadura Militar e Constituição de 1988. Jus.com.br. Disponível em: Direito, Ditadura Militar e Constituição de 1988 - Jus.com.br | Jus Navigandi. Acesso em: II set 2021. 


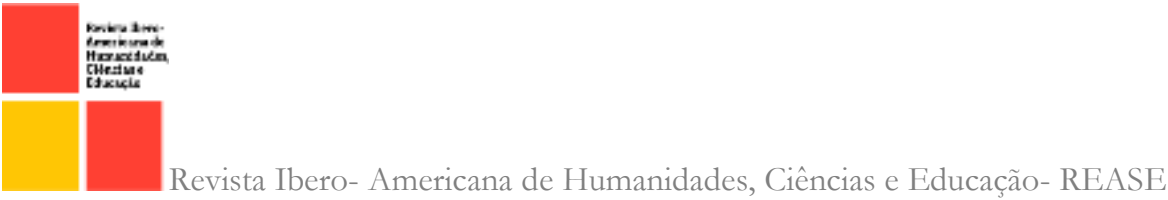

CÂMARA, João Batista Drummond Câmara.Governança Ambiental No Brasil: Ecos do Passado. Recebido em 24 de janeiro de 2009. Rev. Sociol. Polít., Curitiba, v. 21, n. 46, p. I25I46, 2013.

CAMPOS. Carlos Alexandre de Azevedo. Da inconstitucionalidade por omissão ao "Estado de coisas inconstitucional". 2015. 248 f. Tese (Doutorado em Direito) Universidade do Estado do Rio de Janeiro. Rio de Janeiro, 2015.

CARNEIRO, Rafael Araripe; CORREAA, Felipe Santos; PARCA, Túlio da Luz. O conceito de estado de coisas inconstitucional em matéria ambiental no Brasil. LEXLATIN. 2020. Disponível em: https://br.lexlatin.com/opiniao/o-conceito-de-estadode-coisas-inconstitucional-em-materia-ambiental-no-brasil. Acesso em: I8 ago 202I.

DESMATAMENTO acumulado dos últimos ir meses cresceu cerca de 51\% na Amazônia. Imazon. 202I. Disponível em: https://imazon.org.br/imprensa/desmatamentoacumulado-dos-ultimos-II-meses-cresceu-5I-na-amazonia-aponta-imazon/. Acesso em i8 ago 2021.

DIAS, Thiago dos Santos. A Conferência de Estocolmo - 1972 Para o Direito Ambiental do Brasil. Âmbito Jurídico. 2020. Disponível em: https://ambitojuridico.com.br/cadernos/direito-internacional/a-conferencia-deestocolmo-1972-para-o-direito-ambiental-do-brasil/. Acesso em: I8 ago 2021.

DISTRITO FEDERAL. Supremo Tribunal Federal. Medida Cautelar Na Arguição De Descumprimento De Preceito Fundamental 347. Relator: Min. Marco Aurélio. o9 de setembro de 2015. Acórdão. Disponível em: paginador.jsp (stf.jus.br). Acesso em: I2 set 2021.

DISTRITO FEDERAL. Supremo Tribunal Federal. Arguição De Descumprimento De Preceito Fundamental 708. Número Único: 0024408-68.2020.1.oo.oooo. Relator: Min. Roberto Barroso. Processo Eletrônico. 30 de junho de 2020. Disponível em: Supremo Tribunal Federal (stf.jus.br). Acesso em: I2 set. 2021.

ESTOCOLMO. A Conferência das Nações Unidas sobre o Meio Ambiente Humano. 1972. Disponível em: http://www.direitoshumanos.usp.br/index.php/MeioAmbiente/declaracao-de-estocolmo-sobre-o-ambiente-humano.html. Acesso em: is ago 2021.

FUNDO NACIONAL sobre mudança do clima. Ministério do Meio Ambiente. 2012. Disponível em: https://antigo.mma.gov.br/responsabilidade-socioambiental/producao-econsumo-sustentavel/consumo-consciente-de-embalagem/solucoes/itemlist/category/4Ifundo-nacional-sobre-mudanca-do-clima.html?start=14. Acesso em: I6 ago 2021.

GATES, Bill. Como evitar um desastre climático: as soluções que temos e as inovações necessárias. I ed. São Paulo: Companhia das Letras, 202I. 
MACHADO, Paulo Affonso Leme. Direito Ambiental Brasileiro. 2i ed. São Paulo: Malheiros, 2013.

MATTHES, Rafael. Manual de direito ambiental. I ed. São Paulo: Rideel, 2020.

MILARÉ, Édis. Direito do Ambiente. 9 ed. rev. São Paulo: Editora Revista dos Tribunais, 2014 .

MORAES, Alexandre de. Direito constitucional. ı8 ed. São Paulo: Atlas, 2005.

MOURA, Emerson Affonso da Costa et al. Revista De Direito Público Contemporâneo.Instituto de EstudiosConstitucionales da Venezuela e Universidade Federal do Rio de Janeiro do Brasil, a.2, v. 2 ed. 2, p.21, jan/jun 2017. 